\title{
ISUOG Education
}

2020

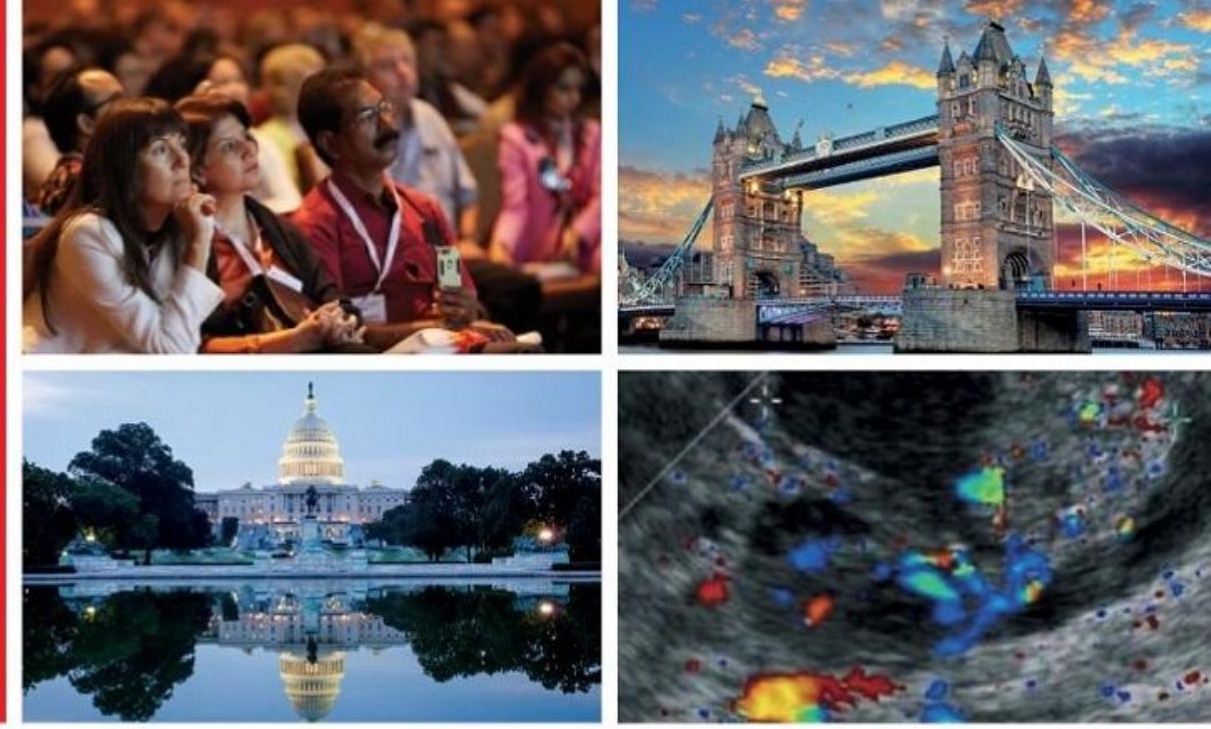

ISUOG delivers quality education courses internationally in Ultrasound in Obstetrics and Gynecology, providing up-to-date research and clinical guidance for a range of topics and professional levels. Our courses are dynamic, interactive and provide delegates with practical tips as well as excellent networking opportunities.
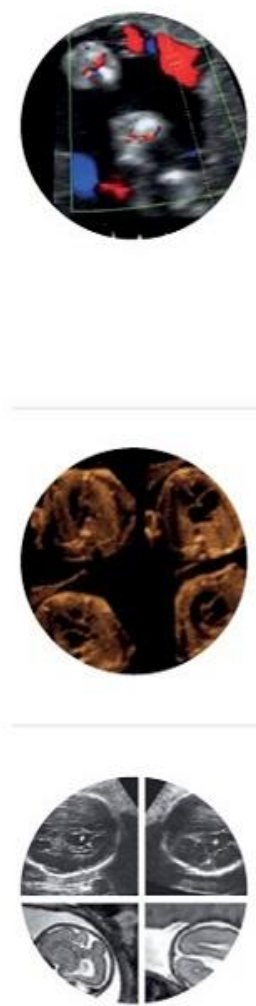

Modern management in twins: All you need to know 4 February 2020

Texas, USA and live streamed worldwide Course Chairs: Lorraine Dugoff (USA), Asma Khalil (UK), Magda Sanz (USA), Joanne Stone (USA)

In association with

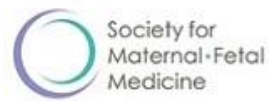

Advances in fetal echocardiography 21 - 22 February 2020

London, UK and live streamed worldwide

Course Chairs: Dario Paladini (Italy), Julene Carvalho (UK)

State of the art ultrasound in pregnancy 16 - 18 April 2020

Washington, USA and live streamed worldwide Course Chairs: Lorraine Dugoff (USA),

Aris Papageorghiou (UK), Laurent Salomon (France), Lynn Simpson (USA), Joanne Stone (USA)

In association with

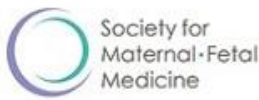

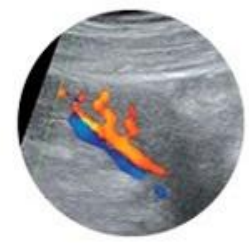

Doppler and maternal vascular imaging 23 - 24 July 2020

London, UK and live streamed worldwide

Course Chairs: Christoph Lees (UK) and Asma Khalil (UK)

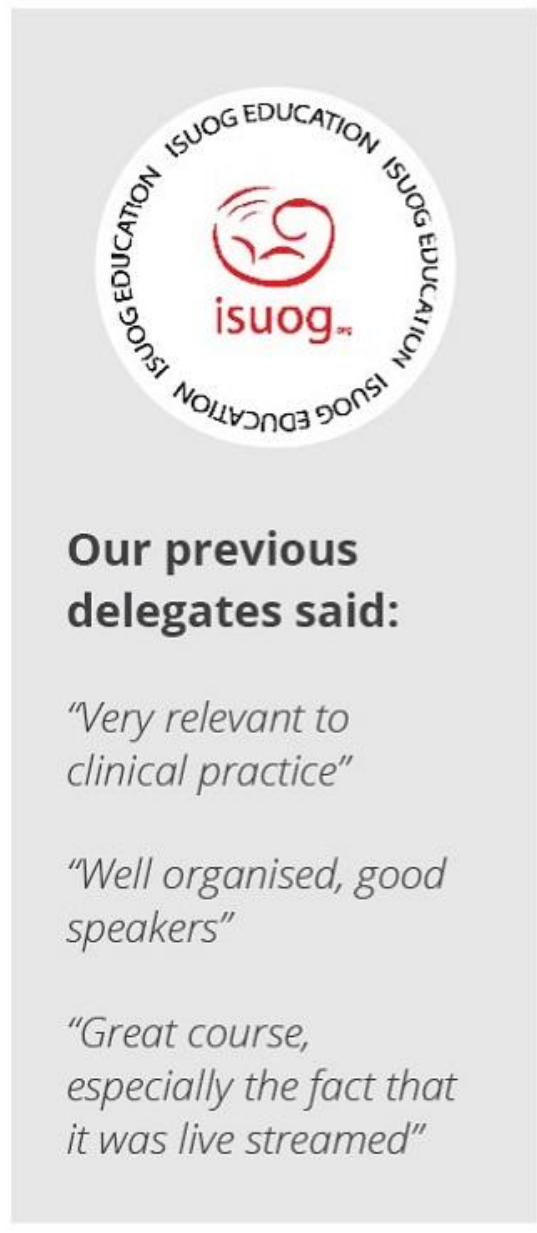

Register now at: isuog.org/events

Discounts available for ISUOG members

Please note the speakers are subject to change at any time. 
Outcome of selective intrauterine growth restriction in monochorionic twin pregnancies at 16, 20 or 30 weeks according to the new consensus definition

Isabel COUCK, $\mathrm{MD}^{1}$, Sophie PONNET, $\mathrm{MD}^{1}$, Jan DEPREST, MD $\mathrm{PhD}^{1,2}$, Roland DEVLIEGER, MD PhD ${ }^{1}$, Luc DE CATTE, MD PhD ${ }^{1}$, Liesbeth LEWI, MD PhD. ${ }^{1}$

${ }^{1}$ Department of Obstetrics and Gynaecology, University Hospitals Leuven; Department of Development and Regeneration, Biomedical Sciences, KULeuven, Belgium

2 Institute for Women's Health, University College London Hospital, London, United Kingdom

Corresponding author:

Liesbeth LEWI, MD PhD.

Fetal Medicine Unit, Dept. Obstetrics \& Gynaecology, University Hospitals Leuven, Herestraat 49, 3000 Leuven, Belgium.

E-mail: liesbeth.lewi@uzleuven.be

\section{Short title: sIUGR in monochorionic twins}

KEYWORDS: Monochorionic twin pregnancy, growth restriction, discordance, definition, outcome 


\section{CONTRIBUTION}

\section{What are the novel findings of this work?}

Several definitions are used to define selective intrauterine growth restriction (sIUGR) in monochorionic twin pregnancies. Recently, a new consensus definition has been proposed to define sIUGR using a Delphi procedure. Although sIUGR has a better outcome than twintwin transfusion syndrome (TTTS), the use of different definitions and reporting on tertiary referral cases make it difficult to estimate the true outcome.

\section{What are the clinical implications of this work?}

In an unselected cohort of monochorionic twin pregnancies followed from the first trimester, the survival rate of isolated sIUGR is more than $90 \%$. The subsequent development of TTTS, absent or reversed end-diastolic flow in the umbilical artery of the smaller twin and the presence of a major anomaly adversely affect survival in sIUGR. 


\begin{abstract}
:
OBJECTIVES: Recently, new criteria have been proposed to define selective intrauterine growth restriction (sIUGR) in monochorionic pregnancies based on the Delphi procedure. We report the outcome of sIUGR diagnosed according to this new consensus definition: either an estimated fetal weight $(\mathrm{EFW})$ of 1 twin $<3^{\text {rd }}$ centile or 2 of the following: EFW or abdominal circumference of 1 twin $<10^{\text {th }}$ centile, EFW discordance $\geq 25 \%$ or umbilical artery pulsatility index of the smaller twin $>95^{\text {th }}$ centile.

METHODS: We performed a retrospective analysis of the outcome of sIUGR diagnosed at 16,20 or 30 weeks in a cohort of monochorionic diamniotic twin pregnancies followed from the first trimester. sIUGR was defined using the Delphi consensus definition. We used uniand multivariate generalized estimated equation modelling to identify predictors of survival.

RESULTS: We analysed 675 pregnancies, of which 177 (26\%) were diagnosed with sIUGR at 16,20 or 30 weeks. The overall survival rate was $313 / 354$ (88\%) with in 146/177 (82\%) survival of both twins, 21/177 (12\%) survival of 1 and 10/177 (6\%) loss of both twins. Subsequent TAPS developed in 6/177 (3\%) and TTTS in 17/177 (10\%). All TAPS fetuses survived. Survival in TTTS was 22/34 (65\%) compared with 279/308 (91\%) in isolated sIUGR (without TAPS or TTTS) ( $<$ 0.001). Most sIUGR cases were type I $(110 / 177 ; 62 \%)$ with a survival rate of $212 / 220(96 \%)$ as compared with $12 / 22(55 \%)$ in type II (p < 0.001$)$ and 55/66 $(83 \%)$ in type III $(\mathrm{p}=0.006)$. The majority of sIUGR pregnancies $(130 / 177 ; 73 \%)$ was first diagnosed at 16 and/or 20 weeks (early-onset) with survival of 221/260 (82\%) as compared to $92 / 94(98 \%)$ of sIUGR first diagnosed at 30 weeks (late-onset) $(\mathrm{p}<0.001)$. A major anomaly in at least one twin was present in 28/177 (16\%) sIUGR cases. For these pregnancies, survival was $39 / 56(70 \%)$, compared to $274 / 298(92 \%)$ for those without anomalies ( $\mathrm{p}<0.001)$. Subsequent TTTS (OR 0.18; 95\% CI [0.06-0.52]), sIUGR type II (OR 0.06; 95\% CI [0.02-0.24]) and type III (OR 0.21; 95\% CI [0.07-0.60]) and a major anomaly
\end{abstract}


in one twin (OR 0.12; 95\% CI [0.04-0.34]) independently determined survival, but not the time at first diagnosis.

CONCLUSIONS: Isolated sIUGR is associated with a $90 \%$ survival rate. The subsequent development of TTTS, absent or reversed end-diastolic flow in the umbilical artery of the smaller twin and the presence of a major anomaly adversely affect survival in sIUGR. 


\section{INTRODUCTION}

Monochorionic twins are expected to be the same size, as they have the same genetic growth potential. However, external factors may affect their growth differently. As such, the placenta may be unequally divided or the net intertwin transfusion may be unidirectional, resulting in a weight difference between the twins. ${ }^{1-3}$ For clinicians, it is crucial to know when this difference becomes clinically important. Whereas most studies use an estimated fetal weight $(\mathrm{EFW})$ discordance of more than $20 \%$ or $25 \%^{4-6}$, some define sIUGR as the growth of at least one twin below the $10^{\text {th }}$ centile 7,8 and yet others use a combination of discordance and growth below the $10^{\text {th }}$ centile. ${ }^{9}$ This use of different definitions hampers comparison of data.

Recently, uniform criteria have been proposed to define sIUGR using the Delphi consensus process. According to this new definition, a monochorionic twin pregnancy is classified as having sIUGR if one of the twins has an EFW $<3^{\text {rd }}$ centile or if at least 2 out of the following 4 parameters are present: EFW of one twin $<10^{\text {th }}$ centile, abdominal circumference of one twin $<10^{\text {th }}$ centile, EFW discordance $\geq 25 \%$ and umbilical artery pulsatility index of the smaller twin $>95^{\text {th }}$ centile. ${ }^{10}$

This new Delphi consensus definition has not been validated in clinical practice yet. Therefore, we aim to report the outcome of sIUGR diagnosed at 16, 20 or 30 weeks in a cohort of unselected monochorionic twin pregnancies followed in our institution from the first trimester. We applied the new consensus definition for the diagnosis of sIUGR and determined any predictors of survival. We further aimed to document the prospective survival of sIUGR diagnosed at 16, 20 and 30 weeks. We also compared the accuracy and agreement of this new definition with that of using an EFW discordance of $20 \%$ or more to predict overall survival and birthweight discordance. 


\section{METHODS}

Study population

We performed a retrospective cohort study of ongoing monochorionic diamniotic twin pregnancies diagnosed in the first trimester (11.0-14.0 weeks) between January 2002 and September 2018 at the University Hospitals Leuven. Monochorionic twin pregnancies are routinely referred to our center for a detailed ultrasound examination at 11-14, 16, 20, and 26-30 weeks of pregnancy. In addition to these 4 examinations, patients have a sonographic assessment at least every 2 weeks, either at our center or at the referring institution, detect twin-twin transfusion syndrome (TTTS) or twin-anemia polycythemia sequence (TAPS) in time, as per recommendation. ${ }^{11}$ Patients explicitly referred in the first trimester for invasive testing or because of an anomaly, were not included. Part of this cohort was included in earlier publications. ${ }^{1,4,5,11-15}$ The follow-up protocol used throughout the study period ${ }^{15}$ remained unchanged, except that from 2008 onward, we changed the timing of the last evaluation from 26 weeks to $28-30$ weeks to detect possible cases of spontaneous TAPS and from 2016 onward, we also measured umbilical venous diameters and flow. This study was approved by the ethics committee of our institution (S62017).

TTTS was defined as oligohydramnios in 1 twin (deepest vertical pool (DVP) $<2 \mathrm{~cm}$ ) and polyhydramnios in the other (DVP $>8 \mathrm{~cm}$ before 20 weeks' gestation and DVP $>10 \mathrm{~cm}$ from 20 weeks onwards). Patients with TTTS were offered fetoscopic laser coagulation of the placental anastomoses as first-line treatment. ${ }^{16}$ Selective reduction by umbilical cord coagulation or by intrafetal radiofrequency ablation (RFA) was offered as an alternative, especially if one twin had an anomaly, was deemed to have a poor prognosis or as a back-up if laser coagulation of the entire equator was not feasible. Patients could also opt for termination of pregnancy if TTTS presented before viability. 
TAPS was defined as a peak systolic velocity in the middle cerebral artery of $>1.5$ MoM in the anaemic donor and $<1.0 \mathrm{MoM}$ in the polycythemic recipient in the absence of TTTS or if the haemoglobin difference at birth was $>8 \mathrm{~g} / \mathrm{dL}$ with no or only minuscule anastomoses on placental injection studies. ${ }^{17}$ Patients with TAPS and fetal decompensation were offered fetal therapy with the aim of postponing delivery until after 32 weeks.

Isolated sIUGR in our centre has traditionally been defined as $\geq 20 \%$ difference in EFW or $\geq 25 \%$ difference in birth weight in the absence of TTTS or TAPS. ${ }^{1}$ Isolated sIUGR cases were classified according to the umbilical artery Doppler pattern in the smaller twin's cord at the last evaluation prior to intervention, demise or birth into type I, II or III. ${ }^{18}$ Patients with continuous or intermittent absent end-diastolic flow in the smaller twin were offered weekly sonographic follow-up, irrespective of the discordance. In the pre-viable period, these patients were counselled about the option of selective reduction if there were signs of imminent demise of the smaller twin, such as a persistent reversed a-wave in the ductus venosus, severe oligohydramnios (deepest vertical pool (DVP) $<2 \mathrm{~cm}$ ) with oliguria ${ }^{19}$, hydrops or arrested fetal growth. When parents opted against selective reduction but wanted to protect the larger twin, laser coagulation of placental anastomoses was offered as an alternative if technically feasible. At 28 weeks, patients with continuous or intermittent absent end-diastolic flow in the smaller twin were eligible for in-patient monitoring with a non-stress test 3 times daily and biweekly ultrasound evaluation. Corticosteroids to improve lung maturity were administered on admission. Elective delivery was scheduled between 32 and 33 weeks after a repeat course of lung maturation. ${ }^{20,21}$

If one of the twins was diagnosed with a major anomaly, parents were offered the option of selective reduction. Also, if PPROM occurred before viability, patients had the choice between conservative management and termination of pregnancy.

$\underline{\text { Data collection }}$ 
In spontaneous conceptions, gestational age (GA) was determined by the crown-rump length of the larger twin at the 11-14 weeks scan. In pregnancies resulting from in vitro fertilization, GA was defined using the date of conception in fresh cycles or embryonic age in frozen-thawed cycles. Maternal age, parity and mode of conception were recorded at the time of the first trimester scan. Ultrasound data were collected of the 16, 20, and 30 weeks' scan (range $14+0$ to $18+6$ weeks, $19+0$ to $23+6$ weeks and $26+0$ to $31+6$ weeks, respectively). Experienced sonographers performed the ultrasound scans on Voluson E10/E8/E6/730 (GE Healthcare, Chicago (IL), USA). Ultrasound reports were made using the Astraia software (Astraia software gmbh, Munich, Germany).

Biparietal diameter, head circumference, abdominal circumference and femur length were recorded at each visit. Estimated fetal weight (EFW) was calculated according to the Hadlock IV formula whenever possible. ${ }^{22}$ In twin pairs where either head circumference or femur length was missing, the Warsof formula was used. ${ }^{23}$ The EFW was then compared to the $3^{\text {rd }}$ and $10^{\text {th }}$ centile for $\mathrm{GA}^{24}$ and the abdominal circumference was compared to the $10^{\text {th }}$ centile for $\mathrm{GA}^{25}$ according to Hadlock. Growth discordance was calculated using the following formula: $\left(\mathrm{EFW}_{\text {larger twin }}-\mathrm{EFW}_{\text {smaller twin }}\right) / \mathrm{EFW}_{\text {larger twin. }}$ Also, we measured the umbilical artery Doppler pattern in all twins at each visit near the placental cord insertion. The pulsatility index of the umbilical artery of the smaller twin was compared to the $95^{\text {th }}$ centile for $\mathrm{GA}^{26}$, according to Acharya.

The obstetric and neonatal outcome data were collected after birth. The presence of major congenital anomalies was recorded according to the EUROCAT criteria. A major congenital anomaly was defined as incompatible with life, requiring major surgery for correction or producing significant dysfunction. ${ }^{27}$

\section{Analyses of primary and secondary outcomes}


As a primary outcome, we documented the overall survival rate (up to day 28 of life) and risk of loss of one or both twins of pregnancies diagnosed with sIUGR according to the Delphi consensus definition at 16, 20 or 30 weeks. Loss of one or both twins was defined as fetal or neonatal demise (up to day 28 of life). We also determined the prospective survival of sIUGR at each respective time point (16, 20 and 30 weeks) separately, in order to evaluate survival with advancing gestational age. We excluded cases diagnosed with single or double demise, TTTS or TAPS prior to or at these specific time points, because the diagnosis of isolated sIUGR implies an ongoing twin pregnancy and the absence of TTTS or TAPS. ${ }^{14}$ More specifically, a pregnancy with sIUGR complicated by TTTS at 19 weeks was included in the 16 weeks analysis but no longer in the 20 weeks analysis as this pregnancy would no longer be diagnosed with isolated sIUGR. Likewise, twin pairs diagnosed with a lethal condition (such as bilateral renal agenesis) were also excluded from the time of diagnosis onward.

We further determined possible predictors of overall survival including maternal characteristics (age (years), parity (nulliparous versus multiparous) and mode of conception (spontaneous versus assisted)), subsequent TTTS versus no TTTS, type II or III versus type I sIUGR at the last ultrasound prior to intervention, demise or birth, time of first diagnosis (early-onset $\leq 20$ weeks versus late-onset at 30 weeks) and the presence of a major anomaly. Predictors that were significant in univariate analysis $(\mathrm{p}<0.05)$ were then further included in a multivariate analysis.

As secondary outcomes, we documented the need for fetal intervention and the birth characteristics of sIUGR diagnosed at each time point. We also compared the accuracy of the Delphi consensus definition with that of using an EFW discordance of $\geq 20 \%$ to predict loss of one or both twins and to predict a birth weight discordance of $\geq 25 \%$. Birth weight discordance was calculated in cases with double survival or double loss only. Finally, we 
determined the agreement between the Delphi consensus definition and EFW discordance of $\geq 20 \%$

For the analyses on a fetal level (survival), we used uni- and multivariate generalized estimated equation modelling to account for the clustering of twins in a twin pregnancy. For the analysis on a pregnancy level (loss one or both, survival of one and both, gestational age, discordance, birthweight larger and smaller twin), we compared categorical outcomes using the Chi-square or Fisher's Exact test, as appropriate. For continuous outcomes, we calculated medians and interquartile ranges and conducted the Kruskal-Wallis test with pairwise comparisons using Dunn's procedure to detect differences between groups.

Diagnostic accuracy was assessed by constructing receiver operating characteristics (ROC) curves. We further compared the areas under the curve (AUC) using the test of equality of ROC areas. We documented the agreement between both definitions using Cohen's kappa.

All analyses were performed using STATA 13.1 (StataCorp. 2013. Stata Statistical Software: Release 13. College Station, TX: StataCorp LP). A 2-sided P-value of P <.05 was considered statistically significant. 


\section{RESULTS}

678 monochorionic diamniotic twins were eligible for inclusion. Outcome data were not available for 3 patients who were lost to follow-up. The demographic details and pregnancy outcomes of the remaining 675 patients are specified in Table 1 . The patient flow is illustrated in Figure 1. Mean GA at the time of 16 weeks' scan was $16.5 \pm 0.8$ weeks, 20.6 \pm 0.9 weeks at the 20 weeks' scan and $29.4 \pm 1.5$ weeks at the 30 weeks' scan. The Hadlock formula was used to calculate EFW in nearly all cases, except for 19 twin pairs at 16 weeks (3\%) and 10 twin pairs at 20 weeks $(2 \%)$, where the Warsof formula was used. Hadlock was used in all cases at 30 weeks.

Of the 675 pregnancies included in this study, 177 (26\%) were diagnosed with sIUGR at some time in pregnancy according to the Delphi consensus definition and overall survival was $313 / 354(88 \%)$ with in 146/177 (82\%) survival of both twins, $21 / 177$ (12\%) survival of 1 and 10/177 (6\%) loss of both twins. (Table 2). Loss of one or both twins was present in 31/177 (18\%) of sIUGR cases. TAPS occurred in 6/177 (3\%), whereas 17 out of $177(10 \%)$ developed subsequent TTTS. All TAPS twins survived and were born after 32 weeks. Survival of sIUGR cases that subsequently developed TTTS was 22/34 (65\%), while survival for those who did not develop TAPS or TTTS (isolated sIUGR) was 279/308 (91\%) (p < $0.001)$.

The majority of sIUGR cases were type I $(110 / 177 ; 62 \%)$ and these had the highest survival rate. In 44 of 177 sIUGR pregnancies $(25 \%)$ the smaller twin had continuous or intermittent absent or reversed end-diastolic umbilical artery flow, which was classified as sIUGR type II in 11 and type III in 33 cases with survival rates of 55\% (12/22) and 83\% $(55 / 66)$, respectively $(\mathrm{p}=0.006)$. Loss of one or both occurred in 7/11 (64\%) Type II cases and 9/33 (27\%) Type III cases $(\mathrm{p}=0.067)$ 
An intervention was performed in the majority of cases with subsequent TTTS (82\%) and with sIUGR type II (55\%), while it was performed in $21 \%$ of cases with type III sIUGR and rarely in type I $(2 \%)(\mathrm{p}<0.001)$. All isolated sIUGR cases that underwent intervention $(15 / 154 ; 10 \%)$ were either complicated by co-existing anomalies ( 9 out of 15$)$ or showed signs of imminent demise of the growth-restricted twin (6 out of 15) (Supplementary Table S1).

The characteristics of pregnancies with early- and late-onset sIUGR are shown in Table 3. The majority of sIUGR pregnancies $(130 / 177 ; 73 \%)$ were first diagnosed at 16 and/or 20 weeks (early-onset) with survival of 221/260 (82\%). When sIUGR was first diagnosed at 30 weeks (late-onset), the survival rate was 92/94 (98\%). Of the 130 cases with early-onset sIUGR, 38 (29\%) were type II or III at first diagnosis. In contrast, only 2 out of 47 late-onset cases (4\%) presented as type III and none were type II ( $p=0.001$ ). In 6/38 (16\%) early-onset cases with abnormal umbilical artery Doppler in the smaller twin, the type III Doppler pattern normalized, and the pregnancies continued as type I. All cases that were diagnosed as type II remained so. In contrast, 13/92 early-onset cases (14\%) were classified as type I at first diagnosis but progressed to type II (4 cases) or III ( 9 cases) later on. Of the 45 late-onset cases with type I, only 1 (2\%) progressed to type III.

A major anomaly in at least one twin was present in 28 out of 177 (16\%) sIUGR cases versus $34 / 498(7 \%)$ of pregnancies without sIUGR $(\mathrm{p}<0.001)$. For fetuses from pregnancies with sIUGR and a major anomaly in at least one twin, the survival rate was 39/56 (70\%), compared with 274/298 (92\%) for those without major anomalies ( $\mathrm{p}<0.001)$. All major anomalies occurred in pregnancies with early-onset sIUGR, except for a critical pulmonary artery stenosis in a larger twin that occurred in a pregnancy with late-onset sIUGR. Therefore, $27 / 130(21 \%)$ twin pairs with early-onset sIUGR also had a major anomaly. In all instances, only one was affected, except for one pregnancy where both had symptomatic 
cytomegalovirus infection. The smaller twin was affected in 21 out of the 26 remaining cases $(81 \%)$

Univariate analysis revealed that maternal characteristics such as age, parity and mode of conception were not associated with survival, in contrast to subsequent TTTS, Type II and III sIUGR, early-onset sIUGR and the presence of a major congenital anomaly. In multivariate analysis, subsequent TTTS, type II and III sIUGR, and the presence of a major anomaly remained significantly associated with decreased survival (Table 4).

The prospective outcomes per time point are illustrated in Supplementary Tables S2 to S4. At 16, 20 and 30 weeks, 89, 83 and 102 cases were diagnosed with sIUGR using the Delphi consensus definition and the prospective survival rate was $80 \%, 92 \%$ and $98 \%$, respectively. At 20 weeks, the survival for type II-III sIUGR was 51/56 (91\%) as compared with $41 / 62(66 \%)$ at 16 weeks. The proportion of cases with subsequent TTTS decreased from $16 \%$ to $7 \%$ and $1 \%$ at 16,20 and 30 weeks, respectively.

Of the 675 included pregnancies, $106(16 \%)$ were complicated by the loss of one or both twins. A birth weight discordance of $\geq 25 \%$ was observed in 71 out of $600(12 \%)$ twin pairs where both were either live born or stillborn. Both the Delphi consensus definition and $a \geq 20 \%$ discordance cut-off were significantly associated with loss of one or both twins and birth weight discordance of $\geq 25 \%$ at 16, 20 and 30 weeks (Table 5). The AUC between both definitions did not differ and was poor (AUC between 0.52-0.64) to predict loss of one or both twins and fair (AUC between $0.70-0.82$ ) to predict a birth weight discordance of $\geq 25 \%$ (Table 6). Only at 30 weeks, the $\geq 20 \%$ cut-off had a higher AUC (0.816) than the Delphi consensus definition $(0.753, p=0.025)$ to predict birthweight discordance of $\geq 25 \%$ (Figure 2). The agreement between both definitions was moderate to good (kappa's coefficient between $0.58-0.64$ ) at all time points. 


\section{DISCUSSION}

Our series is the first to report on the outcome of sIUGR according to the new Delphi consensus definition in an unselected cohort of monochorionic twins. Isolated sIUGR is associated with a more than $90 \%$ survival rate. Subsequent TTTS, absent or reversed enddiastolic flow in the umbilical artery of the smaller twin and the presence of a major anomaly adversely affect survival in sIUGR, but not the timing of onset. Nevertheless, as pregnancy progresses, the survival improves from $80 \%$ at 16 weeks to $98 \%$ at 30 weeks.

The development of TTTS significantly decreased survival. This is in contrast with the study by Monaghan et al. where there was no significant difference in survival between isolated sIUGR $(86 \%)$ and sIUGR complicated by TTTS $(70 \%) .{ }^{28}$ However, they report on a referral population, which likely introduces a bias towards more severe cases. They observed $86 \%$ double survival in sIUGR type I, compared to our $95 \%$, which is more in line with other studies. ${ }^{18,29}$ It is counterintuitive to assume that subsequent TTTS will not worsen the outcome. There is consensus that TTTS requires an intrauterine intervention and is the main cause of mortality in monochorionic twins ${ }^{15}$, whereas isolated sIUGR is mostly managed expectantly and has a more "benign" course. In our study, 10\% of sIUGR pregnancies developed TTTS. Unfortunately, we cannot identify the sIUGR pregnancy that will ultimately progress to TTTS. ${ }^{30-33}$ Therefore, it is important to caution parents that the outcome of sIUGR is expected to be good, provided no TTTS develops.

Umbilical artery Doppler in the smaller twin also affects survival: from $96 \%$ in type I sIUGR, over $83 \%$ in type III to 55\% in type II. Type II and type III Doppler are independent predictors of survival. As known, expectant management of type II-III sIUGR is associated with a survival rate of $50-85 \% .^{7,19}$ In cases treated with laser therapy, overall survival is 53$64 \%^{7,34}$, while this is around $47 \%$ for pregnancies undergoing cord occlusion. ${ }^{6}$ In our study, $70 \%$ of sIUGR type II-III cases were managed expectantly. 
Major congenital anomalies were more frequent in the sIUGR group and were associated with lower survival. About a third (9/28) underwent a fetal intervention, mostly selective reduction. One in 5 pregnancies with early-onset sIUGR had a major anomaly in at least one twin, while this was rarely the case in late-onset sIUGR. Therefore, the diagnosis of early-onset sIUGR should prompt a detailed anatomic examination of the smaller twin.

Timing of onset of sIUGR was not independently associated with survival, but analysis of prospective survival at 16, 20 and 30 weeks showed improving survival rates. This is probably related to loss of the most severe cases. Previous studies focused on the outcome of sIUGR, irrespective of gestational age. ${ }^{18,29}$

A major strength of our series is that we assessed the Delphi consensus definition in a cohort of unselected monochorionic twin pregnancies. Others have used different definitions of sIUGR and reported outcome of tertiary referral centers, usually from the time of referral, making it difficult to compare series and likely introducing selection bias towards more

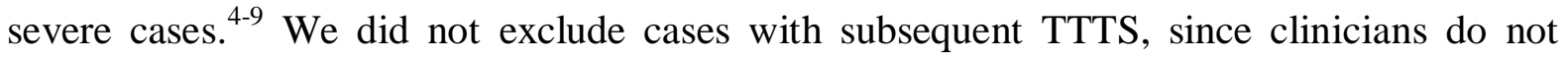
know which sIUGR pregnancies will eventually develop TTTS. This is an important difference compared to other studies that exclude TTTS cases and therefore give more optimistic survival estimates. ${ }^{35,36}$ Likewise, we specifically chose to only exclude lethal anomalies, from the time of diagnosis onwards. In clinical practice, not all anomalies are picked up in early pregnancy. Another strength of our study is that we adhered to a uniform follow-up protocol for all monochorionic diamniotic twins with extensive Doppler measurements.

A weakness of our study is the low number of type II sIUGR cases: only $6 \%$ of isolated sIUGR pregnancies and $1.5 \%$ of our total population. Gratacos et al. reported that $22 \%$ of sIUGR patients had type II Doppler, but they studied patients between 16 and 28 weeks, while sIUGR that was picked up at 30 weeks in our series, was mostly type I and 
never type II. Furthermore, they reported on a tertiary referral population, resulting in a low fraction of type I cases (29\%). ${ }^{18}$ Likewise, Ishii et al. reported a prevalence of type II Doppler of $54 \%$ in sIUGR cases referred to tertiary care before 26 weeks. ${ }^{19}$ It is reasonable to assume that cases with persistent abnormal Doppler are more easily referred. Also, type III is often misclassified as type II, as the intermittent Doppler anomalies are missed when sampling is not done at the site of placental cord insertion.

Another potential comment is that we did not exclude the $10 \%$ of sIUGR cases that underwent a fetal intervention. Some may feel that our analysis is therefore biased, as performing selective reduction automatically reduces survival. However, 9 out of these 15 cases had major anomalies. In the remaining 6, demise was deemed imminent. Parents are usually counselled about the option of intrauterine surgery in these scenarios. Nevertheless, the survival rate of isolated sIUGR in our cohort was still $91 \%$. Finally, our series does not address the neonatal and long-term neurodevelopmental outcome, which is obviously of crucial importance as well.

We showed that there was no difference between the new Delphi consensus definition of sIUGR and a $\geq 20 \%$ discordance in EFW to predict loss of one or both twins and birth weight discordance, except at 30 weeks when the $20 \%$ discordance cut-off was more accurate. However, both methods remain poor in predicting loss of one or both twins. This may be because only 17 out of all 82 TTTS cases occurred in sIUGR pregnancies and TTTS is the main cause of loss in monochorionic pregnancies. ${ }^{15}$ As the Delphi consensus definition requires reference curves and the assessment of multiple variables, the $20 \%$ cut-off may be easier to use in daily clinical practice to select cases for increased surveillance. The Delphi consensus definition could then be reserved for uniform outcome reporting in a research setting. 


\section{CONCLUSION}

Our study shows that isolated sIUGR, as defined by the new consensus definition, is associated with a more than $90 \%$ survival rate. Subsequent TTTS, absent or reversed enddiastolic flow in the umbilical artery of the smaller twin and the presence of a major anomaly, but not the timing of onset, independently determine the survival in sIUGR.

\section{ACKNOWLEDGEMENT}

We would like to thank the referring physicians for sending their patients to our centre for alternate follow-up.

Disclosure statement: The authors report no conflict of interest.

Financial support: This study was funded by a grant from the Fund for Academic Research of the University Hospitals Leuven, Belgium; LL is the recipient of a grant of "Fonds voor Wetenschappelijk Onderzoek" (FWO grantnr: 1804718N) 


\section{REFERENCES}

1. Lewi L, Gucciardo L, Huber A, Jani J, Van Mieghem T, Done E, Cannie M, Gratacos E, Diemert

A, Hecher K, Lewi P, Deprest J. Clinical outcome and placental characteristics of monochorionic diamniotic twin pairs with early- and late-onset discordant growth. Am J Obstet Gynecol. 2008;199(5):511 e1-7.

2. Fick AL, Feldstein VA, Norton ME, Wassel Fyr C, Caughey AB, Machin GA. Unequal placental sharing and birth weight discordance in monochorionic diamniotic twins. Am J Obstet Gynecol. 2006;195(1):178-83.

3. Lewi L, Cannie M, Blickstein I, Jani J, Huber A, Hecher K, Dymarkowski S, Gratacos E, Lewi P, Deprest J. Placental sharing, birthweight discordance, and vascular anastomoses in monochorionic diamniotic twin placentas. Am J Obstet Gynecol. 2007;197(6):587 e1-8.

4. Ortibus E, Lopriore E, Deprest J, Vandenbussche FP, Walther FJ, Diemert A, Hecher K, Lagae L, De Cock P, Lewi P, Lewi L. The pregnancy and long-term neurodevelopmental outcome of monochorionic diamniotic twin gestations: a multicenter prospective cohort study from the first trimester onward. Am J Obstet Gynecol. 2009;200(5):494 e1-8.

5. Van Mieghem T, Deprest J, Klaritsch P, Gucciardo L, Done E, Verhaeghe J, Lewi L. Ultrasound prediction of intertwin birth weight discordance in monochorionic diamniotic twin pregnancies. Prenat Diagn. 2009;29(3):240-4.

6. Chalouhi GE, Marangoni MA, Quibel T, Deloison B, Benzina N, Essaoui M, Al Ibrahim A, Stirnemann J, Salomon L, Ville Y. Active management of selective intrauterine growth restriction with abnormal Doppler in monochorionic diamniotic twin pregnancies diagnosed in the second trimester of pregnancy. Prenat Diagn. 2013;33(2):109-15.

7. Gratacos E, Antolin E, Lewi L, Martinez JM, Hernandez-Andrade E, Acosta-Rojas R, Enriquez G, Cabero L, Deprest J. Monochorionic twins with selective intrauterine growth restriction and intermittent absent or reversed end-diastolic flow (Type III): feasibility and perinatal outcome of fetoscopic placental laser coagulation. Ultrasound Obstet Gynecol. 2008;31(6):669-75. 
8. Valsky DV, Martinez-Serrano MJ, Sanz M, Eixarch E, Acosta ER, Martinez JM, Puerto B, Gratacos E. Cord occlusion followed by laser cord transection in monochorionic monoamniotic discordant twins. Ultrasound Obstet Gynecol. 2011;37(6):684-8.

9. Parra-Cordero M, Bennasar M, Martinez JM, Eixarch E, Torres X, Gratacos E. Cord Occlusion in Monochorionic Twins with Early Selective Intrauterine Growth Restriction and Abnormal Umbilical Artery Doppler: A Consecutive Series of 90 Cases. Fetal Diagn Ther. 2015.

10. Khalil A, Beune I, Hecher K, Wynia K, Ganzevoort W, Reed K, Lewi L, Oepkes D, Gratacos E, Thilaganathan B, Gordijn S. Consensus definition and essential reporting parameters of selective fetal growth restriction in twin pregnancy: a Delphi procedure. Ultrasound Obstet Gynecol. 2019;53(1):47-54.

11. Dekoninck P, Deprest J, Lewi P, Richter J, Galjaard S, Van Keirsbilck J, Van Calsteren K, Lewi L. Gestational age-specific reference ranges for amniotic fluid assessment in monochorionic diamniotic twin pregnancies. Ultrasound Obstet Gynecol. 2013;41(6):649-52.

12. Cheong-See F, Schuit E, Arroyo-Manzano D, Khalil A, Barrett J, Joseph KS, Asztalos E, Hack K, Lewi L, Lim A, Liem S, Norman JE, Morrison J, Combs CA, Garite TJ, Maurel K, Serra V, Perales A, Rode L, Worda K, Nassar A, Aboulghar M, Rouse D, Thom E, Breathnach F, Nakayama S, Russo FM, Robinson JN, Dodd JM, Newman RB, Bhattacharya S, Tang S, Mol BW, Zamora J, Thilaganathan B, Thangaratinam S; Global Obstetrics Network (GONet) Collaboration. Prospective risk of stillbirth and neonatal complications in twin pregnancies: systematic review and meta-analysis. BMJ. 2016;354:i4353.

13. Klaritsch P, Deprest J, Van Mieghem T, Gucciardo L, Done E, Jani J, Lewi P, Rasmussen S, Lewi L. Reference ranges for middle cerebral artery peak systolic velocity in monochorionic diamniotic twins: a longitudinal study. Ultrasound Obstet Gynecol. 2009;34(2):149-54.

14. Lewi L, Lewi P, Diemert A, Jani J, Gucciardo L, Van Mieghem T, Doné E, Gratacos E, Huber A, Hecher K, Deprest J. The role of ultrasound examination in the first trimester and at 16 weeks' 
gestation to predict fetal complications in monochorionic diamniotic twin pregnancies. Am J Obstet Gynecol. 2008;199(5):493 e1-7.

15. Lewi L, Jani J, Blickstein I, Huber A, Gucciardo L, Van Mieghem T, Doné E, Boes AS, Hecher K, Gratacos E, Lewi P, Deprest J. The outcome of monochorionic diamniotic twin gestations in the era of invasive fetal therapy: a prospective cohort study. Am J Obstet Gynecol. 2008;199(5):514 e1-8.

16. Senat MV, Deprest J, Boulvain M, Paupe A, Winer N, Ville Y. Endoscopic laser surgery versus serial amnioreduction for severe twin-to-twin transfusion syndrome. N Engl J Med. 2004;351(2):13644.

17. Slaghekke F, Kist WJ, Oepkes D, Pasman SA, Middeldorp JM, Klumper FJ, Walther F, Vandenbussche F, Lopriore E. Twin anemia-polycythemia sequence: diagnostic criteria, classification, perinatal management and outcome. Fetal Diagn Ther. 2010;27(4):181-90.

18. Gratacos E, Lewi L, Munoz B, Acosta-Rojas R, Hernandez-Andrade E, Martinez JM, Carreras E, Deprest J. A classification system for selective intrauterine growth restriction in monochorionic pregnancies according to umbilical artery Doppler flow in the smaller twin. Ultrasound Obstet Gynecol. 2007;30(1):28-34.

19. Ishii K, Murakoshi T, Hayashi S, Saito M, Sago H, Takahashi $Y$, Sumie M, Nakata M, Matsushito M, Shinno T, Naruse H, Torii Y. Ultrasound predictors of mortality in monochorionic twins with selective intrauterine growth restriction. Ultrasound Obstet Gynecol. 2011;37(1):22-6.

20. Management of Monochorionic Twin Pregnancy: Green-top Guideline No. 51. BJOG. 2017;124(1):e1-e45.

21. Preterm Labour and Birth. National Collaborating Centre for Women's and Children's Health (UK). London: National Institute for Health and Care Excellence (UK). 2019.

22. Hadlock FP, Harrist RB, Sharman RS, Deter RL, Park SK. Estimation of fetal weight with the use of head, body, and femur measurements--a prospective study. Am J Obstet Gynecol. $1985 ; 151(3): 333-7$. 
23. Combs CA, Rosenn B, Miodovnik M, Siddiqi TA. Sonographic EFW and macrosomia: is there an optimum formula to predict diabetic fetal macrosomia? J Matern Fetal Med. 2000;9(1):55-61.

24. Hadlock FP, Harrist RB, Martinez-Poyer J. In utero analysis of fetal growth: a sonographic weight standard. Radiology. 1991;181(1):129-33.

25. Hadlock FP, Deter RL, Harrist RB, Park SK. Estimating fetal age: computer-assisted analysis of multiple fetal growth parameters. Radiology. 1984;152(2):497-501.

26. Acharya G, Wilsgaard T, Berntsen GK, Maltau JM, Kiserud T. Reference ranges for serial measurements of blood velocity and pulsatility index at the intra-abdominal portion, and fetal and placental ends of the umbilical artery. Ultrasound Obstet Gynecol. 2005;26(2):162-9.

27. EUROCAT. EUROCAT Guide 1.4: Instructions for the registration of congenital anomalies. EUROCAT Central Registry, University of Ulster. 2013.

28. Monaghan C, Kalafat E, Binder J, Thilaganathan B, Khalil A. Prediction of adverse pregnancy outcome in monochorionic diamniotic twin pregnancy complicated by selective fetal growth restriction. Ultrasound Obstet Gynecol. 2019;53(2):200-7.

29. Ishii $K$, Murakoshi T, Takahashi $Y$, Shinno $T$, Matsushita $M$, Naruse $H$, Torii $Y$, Sumie $M$, Nakata M. Perinatal outcome of monochorionic twins with selective intrauterine growth restriction and different types of umbilical artery Doppler under expectant management. Fetal Diagn Ther. 2009;26(3):157-61.

30. Stagnati V, Zanardini C, Fichera A, Pagani G, Quintero RA, Bellocco R, Prefumo F. Early prediction of twin-to-twin transfusion syndrome: systematic review and meta-analysis. Ultrasound Obstet Gynecol. 2017;49(5):573-82.

31. Memmo A, Dias T, Mahsud-Dornan S, Papageorghiou AT, Bhide A, Thilaganathan B. Prediction of selective fetal growth restriction and twin-to-twin transfusion syndrome in monochorionic twins. BJOG. 2012;119(4):417-21. 
32. Van Mieghem T, Eixarch E, Gucciardo L, Done E, Gonzales I, Van Schoubroeck D, Lewi L, Gratacos E, Deprest J. Outcome prediction in monochorionic diamniotic twin pregnancies with moderately discordant amniotic fluid. Ultrasound Obstet Gynecol. 2011;37(1):15-21.

33. Couck I, Mourad Tawfic N, Deprest J, De Catte L, Devlieger R, Lewi L. Does the Site of The Cord Insertion increase the risk of Adverse Outcome, Twin-To-Twin Transfusion Syndrome and Discordant Growth in monochorionic twin pregnancies? Ultrasound Obstet Gynecol. 2017.

34. Peeva G, Bower S, Orosz L, Chaveeva P, Akolekar R, Nicolaides KH. Endoscopic Placental Laser Coagulation in Monochorionic Diamniotic Twins with Type II Selective Fetal Growth Restriction. Fetal Diagn Ther. 2015;38(2):86-93.

35. Khalil AA, Khan N, Bowe S, Familiari A, Papageorghiou A, Bhide A, Thilaganathan B. Discordance in fetal biometry and Doppler are independent predictors of the risk of perinatal loss in twin pregnancies. Am J Obstet Gynecol. 2015;213(2):222.e1-.e10.

36. D'Antonio F, Khalil A, Thilaganathan B. Second-trimester discordance and adverse perinatal outcome in twins: the STORK multiple pregnancy cohort. BJOG. 2014;121(4):422-9. 


\section{FIGURE LEGENDS}

Figure 1: Flowchart illustrating the patients that were included for the analysis of the overall survival of sIUGR diagnosed at 16, 20 or 30 weeks (bold) and for the analysis of the prospective survival at 16,20 or 30 weeks (italic)

* Lethal anomalies excluded at 16 weeks were 2 cases with anencephaly, 1 case with caudal regression syndrome, 1 case with bilateral renal agenesis, 1 case with hypoplastic left heart syndrome and 1 case with mosaic triploidy and trisomy 2 . All these fetuses had a normal cotwin. At 20 weeks, an additional case with bilateral multicystic kidney dysplasia in 1 twin was identified and excluded.

TTTS $=$ twin-twin transfusion syndrome;

IUFD = intra-uterine fetal demise;

$\mathrm{TOP}=$ termination of pregnancy;

TAPS $=$ twin anemia polycythemia sequence

Figure 2: Receiver operating characteristics curve for the prediction of birth weight discordance $\geq 25 \%$

$\mathrm{AUC}=$ area under the curve 


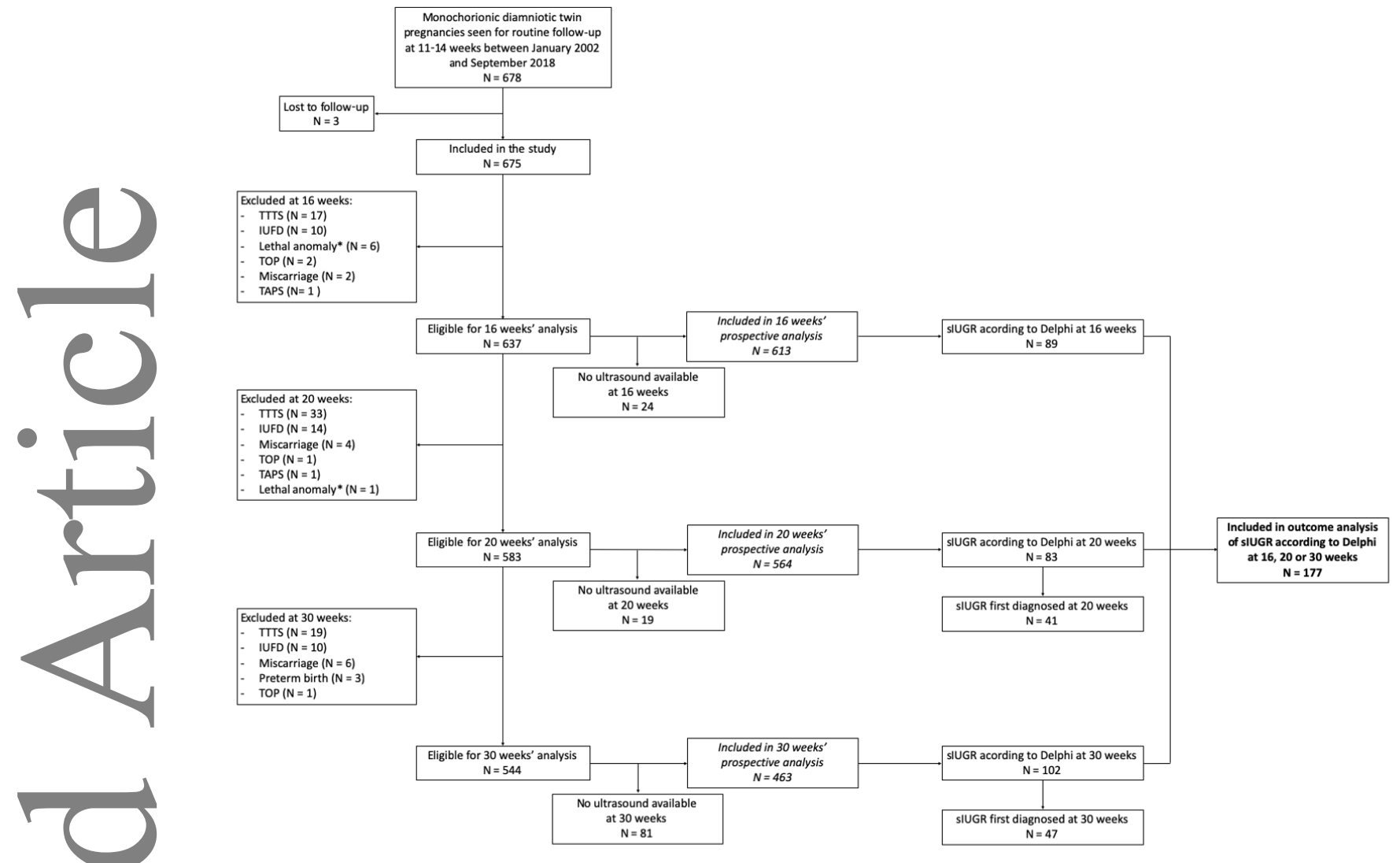

This article is protected by copyright. All rights reserved. 

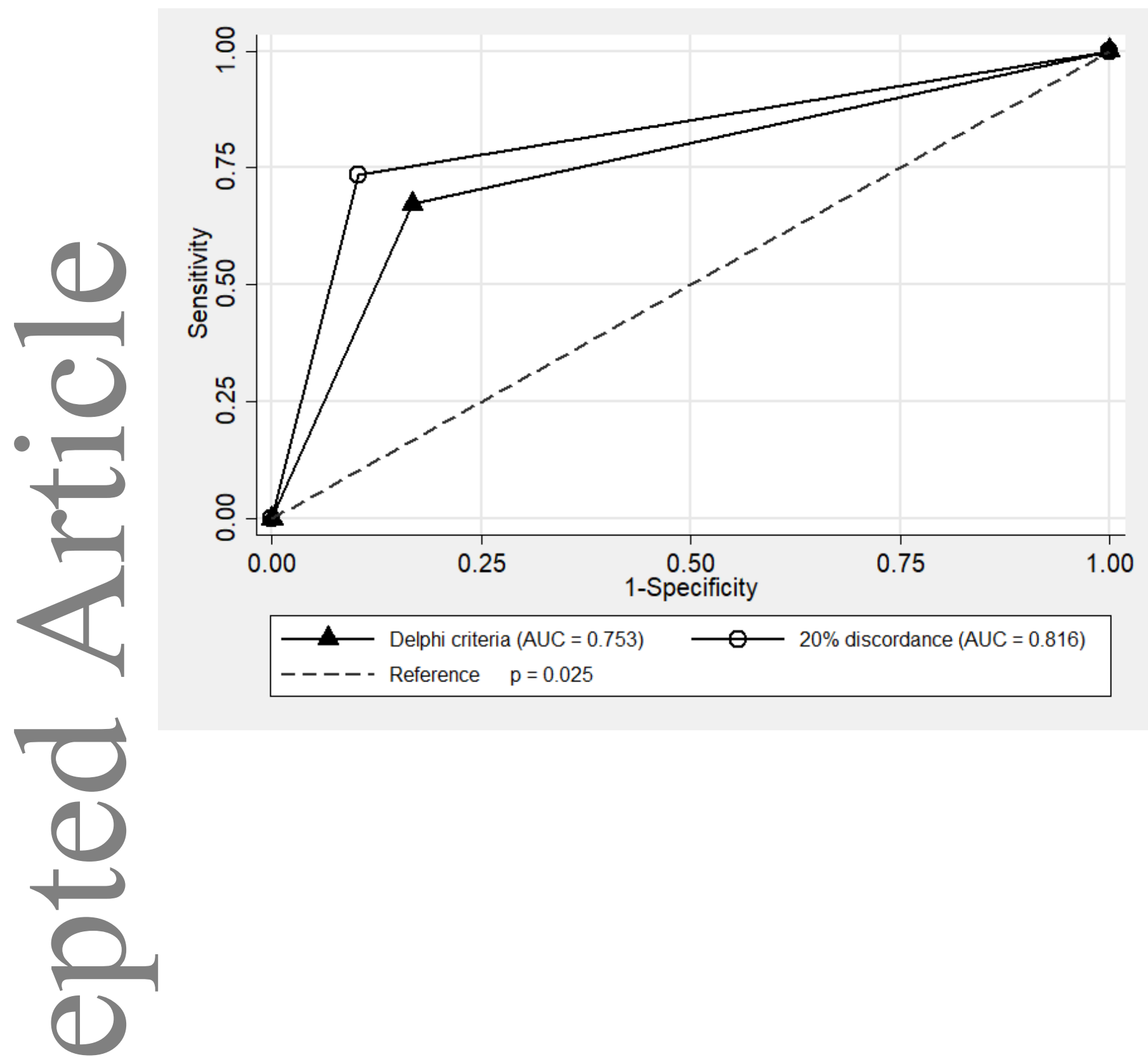

.

,

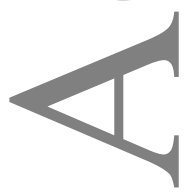

This article is protected by copyright. All rights reserved. 
Table 1: Demographic details and pregnancy outcome of the cohort

\begin{tabular}{|c|c|c|}
\hline \multicolumn{3}{|c|}{ Demographic details ( $N=675$ pregnancies) } \\
\hline & Maternal age (years) & $30 \pm 0.2$ years \\
\hline & Nulliparous & $316 / 675(47 \%)$ \\
\hline & Spontaneous conception & $573 / 675(85 \%)$ \\
\hline & Insemination & $2 / 675(0 \%)$ \\
\hline & Ovulation induction \pm insemination & $20 / 675(3 \%)$ \\
\hline & IVF or ICSI & $80 / 675(12 \%)$ \\
\hline \multicolumn{3}{|c|}{ Fetal complications ( $\mathrm{N}=675$ pregnancies) } \\
\hline & IUFD of 1 or both twins & $75 / 675(11 \%)$ \\
\hline & Twin-twin transfusion syndrome & $82 / 675(12 \%)$ \\
\hline & Twin anemia-polycythemia sequence & $19 / 675(3 \%)$ \\
\hline & Loss of one or both twins & $106 / 675(16 \%)$ \\
\hline \multicolumn{3}{|c|}{ Congenital anomalies ( $\mathrm{N}=675$ pregnancies, 1350 fetuses) } \\
\hline & Pregnancies with major congenital anomalies $\uparrow$ in at least 1 twin & $62 / 675(9 \%)$ \\
\hline & Fetuses with major congenital anomalies $^{1}$ & $68 / 1350(5 \%)$ \\
\hline \multicolumn{3}{|c|}{ Gestational age at birth ( $\mathrm{N}=675$ pregnancies, missing data in 1 ) } \\
\hline & Termination of pregnancy $<24$ weeks & $9 / 674(1 \%)$ \\
\hline & Miscarriage $<24$ weeks & $14 / 674(2 \%)$ \\
\hline & Double IUFD < 24 weeks & $17 / 674(3 \%)$ \\
\hline & Delivery $24 w-27 w 6 d$ & $19 / 674(3 \%)$ \\
\hline & Delivery $28 w-31 w 6 d$ & $82 / 674(12 \%)$ \\
\hline & Delivery $32 w-33 w 6 d$ & $95 / 674(14 \%)$ \\
\hline & Delivery $34 w-36 w 6 d$ & $325 / 674(48 \%)$ \\
\hline & Delivery $\geq 37 w$ & $113 / 674(17 \%)$ \\
\hline \multicolumn{3}{|c|}{ Mode of delivery after 24 weeks ( $N$ = 635 pregnancies, missing data in 9) } \\
\hline & Vaginal delivery & $252 / 626(40 \%)$ \\
\hline & Cesarean section & $365 / 626(58 \%)$ \\
\hline 0 & Cesarean section for second twin & $9 / 626(1 \%)$ \\
\hline \multicolumn{3}{|c|}{ Birth weight of liveborn infants after 24 weeks ( $N=1208$ neonates, missing data in 10) } \\
\hline & $<1500 \mathrm{~g}$ & $158 / 1198(13 \%)$ \\
\hline & $1500-2499 \mathrm{~g}$ & $686 / 1198(57 \%)$ \\
\hline & $>2500 \mathrm{~g}$ & $354 / 1198(30 \%)$ \\
\hline & $\begin{array}{l}\text { Birth weight discordance of } \geq 25 \% \text { in pregnancies with } 2 \\
\text { livebirths }(N=579, \text { missing data in } 5)\end{array}$ & $64 / 574(11 \%)$ \\
\hline \multicolumn{3}{|c|}{ Neonatal complications in livebirths after 24 weeks ( $N=1208$ neonates) } \\
\hline & Neonatal death & $14 / 1208(1 \%)$ \\
\hline & 5-minute Apgar score < 7 (missing values in 43) & $44 / 1165(4 \%)$ \\
\hline & Endotracheal intubation and ventilation (missing data in 60) & $101 / 1148(9 \%)$ \\
\hline & Sepsis (missing data in 60) & $47 / 1148(4 \%)$ \\
\hline
\end{tabular}


Variables are expressed as means \pm standard deviation and proportions (\%). IVF = in vitro fertilization; ICSI = intra-cytoplasmic sperm injection; IUFD = intra-uterine fetal demise ${ }^{1}$ Major congenital anomalies were defined according to the Eurocat criteria (27).

Table 2: Overall survival of sIUGR according to the Delphi consensus definition at 16, 20 or 30 weeks.

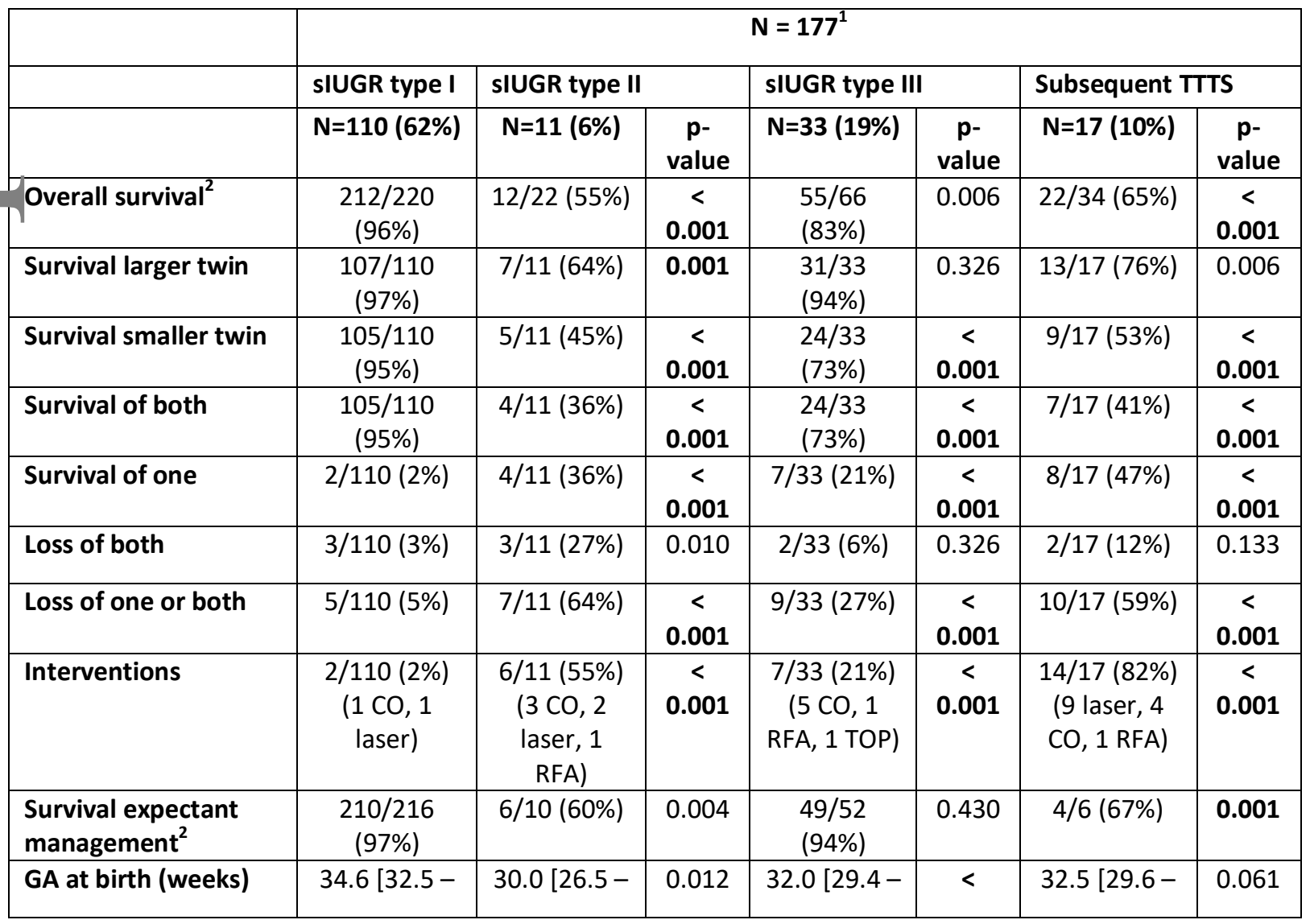




\begin{tabular}{|c|c|c|c|c|c|c|c|}
\hline & 36.1] & 38.0] & & $32.4]$ & 0.001 & $36.2]$ & \\
\hline Birth before 32 weeks & $\begin{array}{c}17 / 110 \\
(15 \%)\end{array}$ & $7 / 11(64 \%)$ & 0.001 & $\begin{array}{l}16 / 33 \\
(48 \%)\end{array}$ & $\begin{array}{c}<< \\
0.001\end{array}$ & $7 / 17(41 \%)$ & 0.019 \\
\hline $\begin{array}{l}\text { Discordance at birth } \\
(\%)^{3}\end{array}$ & $16[8-23]$ & $38[36-41]$ & 0.001 & $27[20-32]$ & $\begin{array}{c}< \\
0.001\end{array}$ & $9[4-26]$ & 0.260 \\
\hline $\begin{array}{l}\text { Birth weight larger } \\
\text { twin (gram) }\end{array}$ & $\begin{array}{c}2140[1875- \\
2440]\end{array}$ & $\begin{array}{c}1200[1120 \\
-1355]\end{array}$ & $\begin{array}{c}< \\
0.001\end{array}$ & $\begin{array}{c}1643[1280 \\
-2000]\end{array}$ & $\begin{array}{c}< \\
0.001\end{array}$ & $\begin{array}{c}1800[1260 \\
-2100]\end{array}$ & 0.039 \\
\hline $\begin{array}{l}\text { Birth weight smaller } \\
\text { twin (gram) }\end{array}$ & $\begin{array}{c}1760[1500- \\
2080]\end{array}$ & $\begin{array}{c}735[680- \\
888]\end{array}$ & $\begin{array}{c}< \\
0.001\end{array}$ & $\begin{array}{c}1175[1000 \\
-1345]\end{array}$ & $\begin{array}{c}< \\
0.001\end{array}$ & $\begin{array}{c}1540[1205- \\
2000]\end{array}$ & 0.094 \\
\hline
\end{tabular}

Data are expressed as medians [interquartile range] or proportions (\%). Analyses are on a pregnancy level unless stated otherwise. To compare the groups, sIUGR type I was set as a reference. Numbers in bold indicate a $p$-value of $\leq 0.001$ and are considered significant after Bonferroni correction for multiple comparisons. TTTS = twin-to-twin transfusion syndrome; sIUGR = selective intra-uterine growth restriction; GA = gestational age; $\mathrm{CO}=$ cord occlusion; RFA = radiofrequency ablation; TOP = termination of pregnancy ${ }^{1} 6 / 177$ patients developed TAPS and were not included. All 12 survived and were born after 32 weeks; ${ }^{2}$ Analysis on a fetal level with correction for clustering of twins within mothers; ${ }^{3}$ Calculated in live born twin pairs.

Table 3: Characteristics of early- and late-onset sIUGR

\begin{tabular}{|c|c|c|c|}
\hline & \multicolumn{2}{|c|}{$\mathrm{N}=177$} & \multirow[b]{2}{*}{ P-value } \\
\hline & $\begin{array}{l}\text { Early-onset slUGR } \\
\text { (N=130; 73\%) }\end{array}$ & $\begin{array}{l}\text { Late onset sIUGR } \\
(\mathrm{N}=47 ; 27 \%)\end{array}$ & \\
\hline Overall survival $^{1}$ & $221 / 260(82 \%)$ & $92 / 94(98 \%)$ & 0.040 \\
\hline Survival larger twin & $118 / 130$ (91\%) & $46 / 47$ (98\%) & 0.189 \\
\hline Survival smaller twin & $103 / 130(79 \%)$ & $46 / 47$ (98\%) & 0.002 \\
\hline Survival of both & $100 / 130(77 \%)$ & $46 / 47$ (98\%) & $<0.001$ \\
\hline Survival of one & $21 / 130(16 \%)$ & $0 / 47(0 \%)$ & 0.001 \\
\hline Loss of both & $9 / 130(7 \%)$ & $1 / 47(2 \%)$ & 0.294 \\
\hline Loss of one or both & $30 / 130(23 \%)$ & $1 / 47(2 \%)$ & $<0.001$ \\
\hline sIUGR type II-III prior to intervention, demise or birth & $41 / 130(32 \%)$ & $3 / 47(6 \%)$ & $<0.001$ \\
\hline Subsequent TTSS & $17 / 130(13 \%)$ & $0 / 47(0 \%)$ & 0.007 \\
\hline Subsequent TAPS & $4 / 130(3 \%)$ & $2 / 47(4 \%)$ & 0.657 \\
\hline Interventions & $29 / 130(22 \%)$ & $0 / 47(0 \%)$ & $<0.001$ \\
\hline${\text { Survival expectant management }{ }^{1}}$ & $189 / 202(94 \%)$ & $92 / 94(98 \%)$ & 0.288 \\
\hline GA at birth (weeks) & $33.6[31.2-36.0]$ & $34.6[32.5-36.0]$ & 0.055 \\
\hline Birth before 32 weeks & $42 / 130(32 \%)$ & $5 / 47(11 \%)$ & 0.004 \\
\hline Discordance at birth (\%) ${ }^{2}$ & $22[12-31]$ & $13[6-19]$ & $<0.001$ \\
\hline Birth weight larger twin (gram) ${ }^{2}$ & $2045[1640-2310]$ & $1995[1680-2270]$ & 0.886 \\
\hline Birth weight smaller twin (gram) ${ }^{2}$ & $1540[1220-2000]$ & $1700[1495-2020]$ & 0.049 \\
\hline
\end{tabular}

Data are expressed as medians [interquartile range] or proportions (\%). Analyses are on a pregnancy level, unless stated otherwise. Numbers in bold indicate a $p$-value of $\leq 0.05$ and are considered significant. TTS = twin-to-twin transfusion syndrome; TAPS = twin anemia polycythemia sequence; GA = gestational age; sIUGR = selective intra-uterine growth restriction classified according to the Delphi consensus criteria. ${ }^{1}$ Analysis on a fetal level with correction for clustering twins within mothers; ${ }^{2}$ Calculated in live born twin pairs. 
Table 4: Univariate and multivariate analysis of predictors for fetal survival in pregnancies that were screen positive according to the Delphi criteria at 16,20 or 30 weeks $(N=354)$

\begin{tabular}{|c|c|c|c|c|}
\hline Predictor & $\begin{array}{l}\text { OR in univariate } \\
\text { analysis } \\
(95 \% \mathrm{Cl})\end{array}$ & $\begin{array}{l}\text { P-value in } \\
\text { univariate } \\
\text { analysis }\end{array}$ & $\begin{array}{l}\text { OR in multivariate } \\
\text { analysis }(95 \% \mathrm{Cl})\end{array}$ & $\begin{array}{l}\text { P-value in } \\
\text { multivariate } \\
\text { analysis }\end{array}$ \\
\hline Maternal age & $\begin{array}{c}0.96 \\
{[0.87-1.07]}\end{array}$ & 0.482 & - & - \\
\hline Assisted conception & $\begin{array}{c}0.48 \\
{[0.19-1.20]} \\
\end{array}$ & 0.115 & - & - \\
\hline Nulliparity & $\begin{array}{c}1.39 \\
{[0.64-3.05]} \\
\end{array}$ & 0.404 & - & - \\
\hline Early diagnosis & $\begin{array}{c}0.12 \\
{[0.02-0.93]}\end{array}$ & 0.043 & $\begin{array}{c}0.49 \\
{[0.06-4.16]}\end{array}$ & 0.514 \\
\hline Subsequent TTTS & $\begin{array}{c}0.18 \\
{[0.08-0.42]}\end{array}$ & $<0.001$ & $\begin{array}{c}0.18 \\
{[0.06-0.52]}\end{array}$ & 0.002 \\
\hline \multicolumn{5}{|l|}{$\begin{array}{l}\text { UA doppler in the } \\
\text { smaller twin prior } \\
\text { to birth, } \\
\text { intervention or } \\
\text { demise }\end{array}$} \\
\hline - Type I & 1.00 & - & 1.00 & - \\
\hline - $\quad$ Type II & $\begin{array}{c}0.07 \\
{[0.02-0.21]}\end{array}$ & $<0.001$ & $\begin{array}{c}0.06 \\
{[0.02-0.24]}\end{array}$ & $<0.001$ \\
\hline - $\quad$ Type III & $\begin{array}{c}0.23 \\
{[0.10-0.58]}\end{array}$ & 0.002 & $\begin{array}{c}0.21 \\
{[0.07-0.60]}\end{array}$ & 0.003 \\
\hline Major anomaly $^{1}$ & $\begin{array}{c}0.12 \\
{[0.05-0.29]}\end{array}$ & $<0.001$ & $\begin{array}{c}0.12 \\
{[0.04-0.34]}\end{array}$ & $<0.001$ \\
\hline
\end{tabular}


$\mathrm{OR}=$ odds ratio; $\mathrm{Cl}=$ confidence interval; sIUGR = selective intra-uterine growth restriction; TTTS = twin-twin transfusion syndrome; $\mathrm{UA}=$ umbilical artery. The analysis was adjusted for the clustering of twins within mothers. ${ }^{1}$ Major congenital anomalies are defined according to the Eurocat criteria (27). 
Table 5: Prediction of sIUGR according to the Delphi consensus definition and the cut-off of $\geq 20 \%$ discordance in estimated fetal weight

\begin{tabular}{|c|c|c|c|c|c|c|c|}
\hline & & $\begin{array}{l}16 \\
\text { weeks }\end{array}$ & $\begin{array}{l}16 \\
\text { weeks } \\
\text { RR } \\
(95 \% \mathrm{Cl})\end{array}$ & $\begin{array}{l}20 \\
\text { weeks }\end{array}$ & $\begin{array}{l}20 \\
\text { weeks } \\
\text { RR } \\
(95 \% \mathrm{Cl})\end{array}$ & $\begin{array}{l}30 \\
\text { weeks }\end{array}$ & $\begin{array}{l}30 \\
\text { weeks } \\
\text { RR } \\
(95 \% \mathrm{Cl})\end{array}$ \\
\hline $\begin{array}{l}\text { Delphi } \\
\text { consensus } \\
\text { definition }\end{array}$ & $\begin{array}{l}\text { Screen positive vs } \\
\text { negative }\end{array}$ & & & & & & \\
\hline & - Incidence & $\begin{array}{l}89 / 612 \\
(15 \%) \\
\text { versus } \\
523 / 612 \\
(85 \%) \\
\end{array}$ & & $\begin{array}{l}83 / 563 \\
(15 \%) \\
\text { versus } \\
480 / 563 \\
(85 \%) \\
\end{array}$ & & $\begin{array}{l}102 / 458 \\
(22 \%) \\
\text { versus } \\
356 / 458 \\
(78 \%) \\
\end{array}$ & \\
\hline & $\begin{array}{l}\text { - Loss of one or } \\
\text { both }\end{array}$ & $\begin{array}{l}27 / 89 \\
(30 \%) \\
\text { versus } \\
47 / 523 \\
(9 \%) \\
\end{array}$ & $\begin{array}{l}4.4 \\
(2.56- \\
7.59)\end{array}$ & $\begin{array}{l}10 / 83 \\
(12 \%) \\
\text { versus } \\
29 / 480 \\
(6 \%) \\
\end{array}$ & $\begin{array}{l}2.13 \\
(1.00- \\
4.56)\end{array}$ & $\begin{array}{l}3 / 102 \\
(3 \%) \\
\text { versus } \\
6 / 356 \\
(2 \%) \\
\end{array}$ & $\begin{array}{l}1.77 \\
(0.43- \\
7.20)\end{array}$ \\
\hline & $\begin{array}{ll} & \text { Birth weight } \\
\text { discordance } \geq \\
25 \%^{1}\end{array}$ & $\begin{array}{l}31 / 68 \\
(46 \%) \\
\text { versus } \\
34 / 491 \\
(7 \%)\end{array}$ & $\begin{array}{l}6.58 \\
(4.35- \\
9.97)\end{array}$ & $\begin{array}{l}37 / 75 \\
(49 \%) \\
\text { versus } \\
24 / 464 \\
(5 \%)\end{array}$ & $\begin{array}{l}9.54 \\
(6.07- \\
14.99)\end{array}$ & $\begin{array}{l}33 / 100 \\
(33 \%) \\
\text { versus } \\
17 / 350 \\
(5 \%)\end{array}$ & $\begin{array}{l}6.79 \\
(3.95- \\
11.67)\end{array}$ \\
\hline $\begin{array}{l}\geq 20 \% \\
\text { discordance }\end{array}$ & $\begin{array}{l}\text { Screen positive vs } \\
\text { negative }\end{array}$ & & & & & & \\
\hline & - Incidence & $\begin{array}{l}92 / 612 \\
(15 \%) \\
\text { versus } \\
520 / 612 \\
(85 \%) \\
\end{array}$ & & $\begin{array}{l}81 / 563 \\
(14 \%) \\
\text { versus } \\
482 / 563 \\
(86 \%) \\
\end{array}$ & & $\begin{array}{l}79 / 458 \\
(17 \%) \\
\text { versus } \\
379 / 458 \\
(83 \%) \\
\end{array}$ & \\
\hline & $\begin{array}{l}\text { - Loss of one or } \\
\text { both }\end{array}$ & $\begin{array}{l}29 / 92 \\
(32 \%) \\
\text { versus } \\
45 / 520 \\
(9 \%)\end{array}$ & $\begin{array}{l}4.86 \\
(2.84- \\
8.30)\end{array}$ & $\begin{array}{l}11 / 81 \\
(14 \%) \\
\text { versus } \\
28 / 482 \\
(6 \%)\end{array}$ & $\begin{array}{l}2.55 \\
(1.21- \\
5.35)\end{array}$ & $\begin{array}{l}2 / 79 \\
(3 \%) \\
\text { versus } \\
7 / 379 \\
(2 \%) \\
\end{array}$ & $\begin{array}{l}1.38 \\
(0.28- \\
6.77)\end{array}$ \\
\hline & $\begin{array}{ll}- & \text { Birth weight } \\
\text { discordance } \geq \\
25 \%^{1}\end{array}$ & $\begin{array}{l}36 / 68 \\
(52 \%) \\
\text { versus } \\
29 / 491 \\
(6 \%)\end{array}$ & $\begin{array}{l}8.96 \\
(5.90- \\
13.62)\end{array}$ & $\begin{array}{l}33 / 73 \\
(45 \%) \\
\text { versus } \\
28 / 466 \\
(6 \%)\end{array}$ & $\begin{array}{l}7.52 \\
(4.85- \\
11.67)\end{array}$ & $\begin{array}{l}36 / 77 \\
(47 \%) \\
\text { versus } \\
14 / 373 \\
(4 \%) \\
\end{array}$ & $\begin{array}{l}12.46 \\
(7.07- \\
21.95)\end{array}$ \\
\hline $\begin{array}{l}\text { Cohen's } \\
\text { kappa } \\
\text { coefficient for } \\
\text { agreement }\end{array}$ & & $\begin{array}{l}0.58 \\
(95 \% \mathrm{Cl} \\
0.49- \\
0.67)\end{array}$ & - & $\begin{array}{l}0.61 \\
(95 \% \mathrm{Cl} \\
0.51- \\
0.70)\end{array}$ & - & $\begin{array}{l}0.64 \\
(95 \% \mathrm{Cl} \\
0.55- \\
0.73) \\
\end{array}$ & - \\
\hline
\end{tabular}

Variables are expressed as proportions (\%) or coefficients $(95 \%$ confidence interval $(\mathrm{CI})) . \mathrm{RR}=$ relative risk. $^{1}$

Calculated in twin pairs where both were live born or both were stillborn. 
Table 6: Area under the curve for receiver operating characteristics curves in the prediction of adverse outcome and $\geq 25 \%$ birth weight discordance

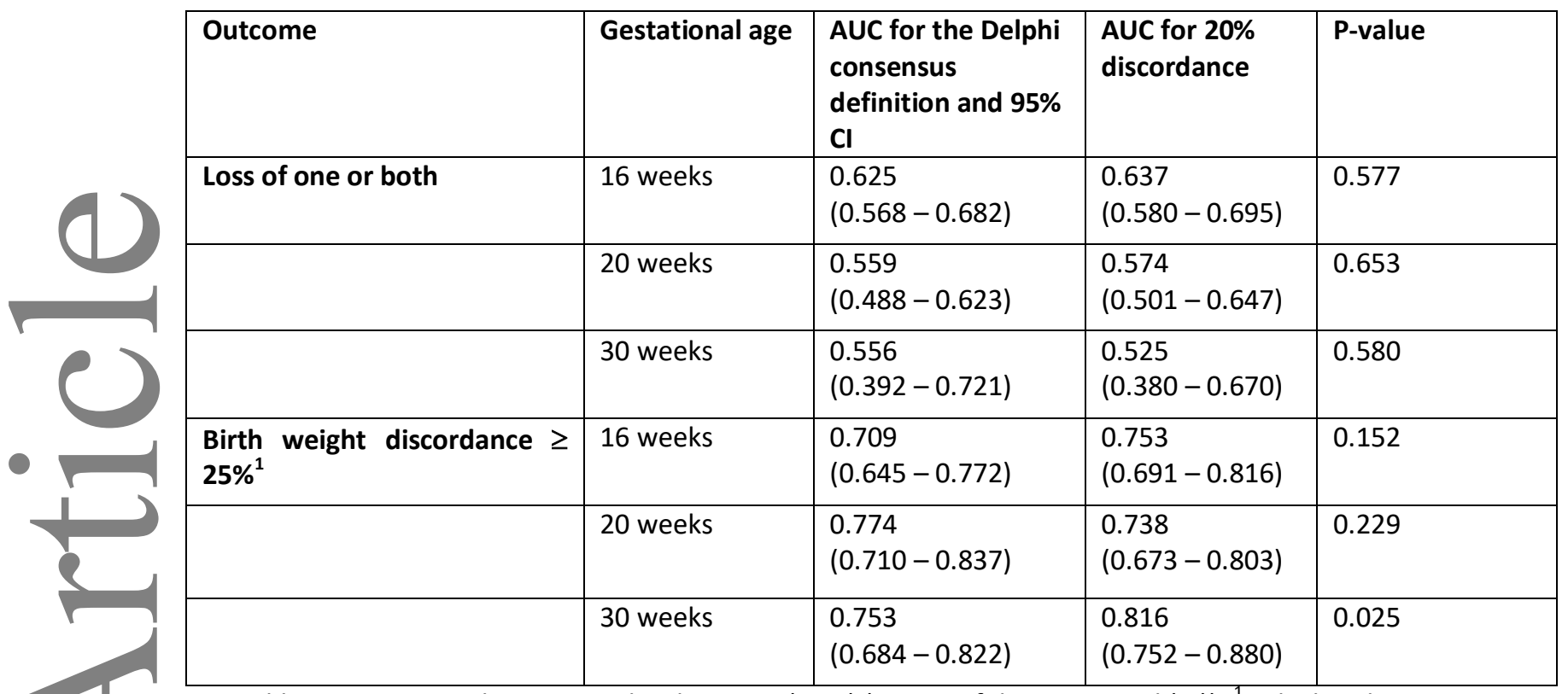

Variables are expressed as area under the curve (AUC) (95\% confidence interval (CI)). ${ }^{1}$ Calculated in twin pairs where both were live born or both were stillborn 